\title{
Características microbiológicas, físico químicas do manjar de ameixa com coco elaborado com Kefir
}

\author{
Microbiological, physical and chemical characteristics of plum blancmange made with Kefir \\ Las características microbiológicas, físico químicas de manjar de ciruela com coco elaborado com
}

Kefir

Recebido: 21/07/2021 | Revisado: 30/07/2021 | Aceito: 02/08/2021 | Publicado: 07/08/2021

\author{
Marina de Souza Brasil da Silva \\ ORCID: https://orcid.org/0000-0002-5587-7526 \\ Universidade Federal do Triângulo Mineiro, Brasil \\ E-mail: marina.brasi1605@gmail.com \\ Mônica Hitomi Okura \\ ORCID: https://orcid.org/0000-0002-9875-9378 \\ Universidade Federal do Triângulo Mineiro, Brasil \\ E-mail: monica.okura@uftm.edu.br
}

\begin{abstract}
Resumo
O Kefir é considerado um alimento probiótico devido aos benefícios associados ao seu consumo, como estimulação do sistema imune, equilíbrio da microbiota intestinal e atividade antimicrobiana. Desta forma, a indústria alimentícia vem se adaptando a nova tendência, estimulando o desenvolvimento de alimentos funcionais. Assim, o presente trabalho tem como objetivo avaliar as características microbiológicas e físico-químicas do manjar de ameixa com coco elaborado com Kefir. Na análise microbiológica foi analisado os coliformes; Salmonella, contagem de bolores, leveduras e lactobacilos (Silva et al (2007) e para as análises físico químicos foram analisados $\mathrm{pH}$, ${ }^{\circ} \mathrm{Brix}$, acidez titulável, teor de gordura, lactose, cálcio e sólidos totais (Brasil 2005). Observou-se no manjar, o decréscimo do pH de 4,21 para 4,12, aumento da acidez de 1,095 para 1,185\%, devido a produção de ácidos orgânicos durante a fermentação alcoólica e diminuição do ${ }^{\circ}$ Brix de 24,67 para 21,67. Além disso, apresentou teor de gordura de 8,51\%, cálcio de $0,159 \%$, lactose de $2,805 \%$ e sólidos totais de $0,679 \%$. Notou-se que o teor de lactose continuou elevado, devido à baixa concentração de grãos de Kefir. Já nas análises microbiológicas não houve presença de coliformes e Salmonella garantindo assim a higiene sanitária do produto. A contagem de bolores e leveduras também estavam

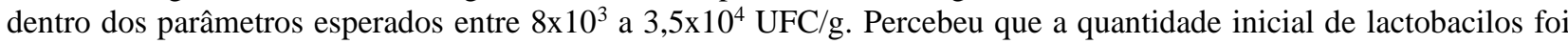
decrescendo ao longo dos dias, chegando a 0 , perdendo a proposta de alimento funcional. Concluímos que é necessário reformular esse produto com uma quantidade maior de kefir para obter um menor teor de lactose.
\end{abstract}

Palavras-chave: Kefir; Manjar de coco; Alimento funcional.

\begin{abstract}
Kefir is considered a probiotic food due to the benefits associated with its consumption, such as immune system stimulation, intestinal microbiota balance and antimicrobial activity against pathogens. Thus, the food industry has been adapting to the new trend by stimulating the development of functional foods. Thereby, the present study aims to evaluate the microbiological and physicochemical characteristics of plum and coconut blancmange made with Kefir In the microbiological analysis were analyzed coliforms; Salmonella, molds counting, yeasts and lactobacilli (Silva et al., 2007) and for the physicochemical analyzes were analyzed $\mathrm{pH}$, ${ }^{\circ}$ Brix, titratable acidity, fat content, lactose, calcium and total solids (Brasil, 2005). A decrease in $\mathrm{pH}$ from 4.21 to 4.12 was observed in the blancmange an increase in acidity from 1.095 to $1.185 \%$, due to the production of organic acids during alcoholic fermentation and a decrease in ${ }^{\circ}$ Brix from 24.67 to 21.67 . In addition, it had a fat content of $8.51 \%$, calcium content of $0.159 \%$, lactose content of $2.805 \%$ and total solids content of $0.679 \%$. It was noted that the lactose content remained high due to the low concentration of Kefir grains. In microbiological analysis there was no presence of coliforms and salmonella thus ensuring the sanitary hygiene of the product. The molds and yeasts counting were also within the expected parameters between $8 \times 103$ to $3.5 \times 104 \mathrm{CFU} / \mathrm{g}$. It was noticed that the initial amount of lactobacilli decreased over the days, reaching 0 and losing the functional food proposition. It is therefore concluded that it is necessary to reformulate this product with a larger amount of kefir to obtain a lower lactose content.
\end{abstract}

Keyword: Kefir; Coconut blancmange; Functional Food. 


\begin{abstract}
Resumen
El Kefir es considerado una comida probiótica gracias a los beneficios asociados a su consumo, como la estimulacion del sistema inmunológico, equilibrio de la microbiota intestinal y actividad antimicrobiana contra patógenos. De esa manera, la industria de los alimentos está adaptándose a esta nueva tendencia estimulando el desarrollo de los alimentos funcionales. Así, esto trabajo tiene como objetivo evaluar las características microbiológicas y físicoquimicas del manjar de ciruela con coco elaborado con Kéfir. En las análisis microbiológicas se analizó los coliformes, Salmonella, recuento de moho, levadura y lactobacilos (Silva et al., 2007) y para las análisis físicoquímicas se estudiaron el pH, Brix, acidez de titulación, contenido en grasa, lactosa, calcio y solidos totales (Brasil, 2005). Se observó uno disminucion del pH de 4,21 a 4,12, un aumento de la acidez de 1,095 para 1,185\%, gracias a la producción de ácidos orgánicos durante la fermentación alcohólica e disminución del brix de 24,67 para 21,67. Además de eso, el producto presentó teor de grasas de $8,51 \%$, calcio de $0,159 \%$, lactosa de $2,805 \%$ y sólidos totales de $0,679 \%$. Se notó que el contenido de lactosa permaneció alto, debido ala baja contenido de granos de Kefir. Pero en las análisis microbiológicas no había la presencia de coliformes, ni de Salmonella, garantizando de esa forma la higiene sanitaria del producto. El recuento de mohos y levaduras también estava dentro de los parámetros esperados entre 8x103 a 3,5x104 UFC/g. Se notó que la cantidad inicial de lactobacilos fue disminuyendo, llegando a 0 , perdiendo la propuesta de alimento funcional. Se concluye que es necesario remodelar esto producto con una cantidad mayor de Kefir para que haya un menor contenido de lactosa.
\end{abstract}

Palabras clave: Kefir; Manjar con coco; Alimento funcionale.

\title{
1. Introdução
}

O aumento da expectativa de vida da população, as novas tecnologias capazes de ajudar a obter mudanças significativas no estilo de vida e o alto custo de médicos e medicação, vem fazendo com que o indivíduo procure novas formas de viver uma vida saudável (Souto et al., 2020).

Como consequência, a indústria de alimentos vem se adaptando entre o consumo de alimentos e a melhora da saúde, assim uma nova tendência são os alimentos funcionais. Os benefícios associados ao consumo desses alimentos se dão pela contribuição de uma melhora no desempenho do organismo consumidor (Gonçalves et al., 2018).

Um alimento funcional é o leite fermentado devido a sua característica probiótica. O produto é obtido a partir da fermentação do leite, que acontece através da ação de bactérias ácidos-lácticas que transformam parte da lactose em ácido láctico. Além disso, durante o processo outros subprodutos são formados como dióxido de carbono, ácido acético, diacetil e alcetaldeído, que ajudam a conferir sabor e aroma característico. O leite fermentado de kefir se diferencia da fermentação láctea convencional pois ocorre tanto a fermentação ácido-lática quanto a alcóolica (Tussolini et al., 2009).

Há milênios, os grãos de kefir vem sendo utilizados para a elaboração de produtos fermentados. A matéria prima da fermentação pode ser oriunda de leites de vaca, cabra, búfala e água (Dornelles et al., 2006). Os grânulos de kefir apresentam uma constituição microbiológica que varia de acordo com a sua região de origem, assim os principais micro-organismos presentes principalmente são as bactérias do gênero lactobacilos e leveduras como as do gênero Saccharomyces, Kluyermyces, Candida e Pichia (Dornelles et al., 2006). Além disso, a composição química desses grãos de kefir são formados de 89-90\% de água, 0,2 de lipídios, 3\% de proteína, 6\% de açúcares e 0,7\% de minerais (Dornellles et al., 2009).

Segundo Santos et al. (2012), apesar do Kefir ser um produto muito antigo, ainda hoje em algumas partes do mundo se desconhecem sua existência. O Kefir é explorado industrialmente em determinadas regiões, principalmente no leste europeu (Paiva, 2013). A Rússia, Canadá, Alemanha, Suécia e Romênia são alguns países que possuem produção de Kefir em escala industrial, mas apesar do consumo se dar em quantidades apreciáveis, o mesmo também é produzido em escala familiar, para consumo próprio (Santos et al., 2012). No Brasil, a produção acontece na maior parte em escala familiar, onde o Kefir vem ganhando adeptos nos últimos anos devido as suas características sensoriais e suas propriedades terapêuticas. Entretanto, em Recife, na empresa Biologicus produz e comercializa o Kefir a partir de grãos oriundos da Europa (Terra, 2007). 
Paiva (2013) comenta que a produção do Kefir em escala industrial é desenvolvida de forma complexa devido à instabilidade na composição microbiana dos grãos ao longo do tempo. Na Rússia, com a produção em escala industrial, são desenvolvidos inúmeros subprodutos, como Danone, a Samaralakto, a Ufamolagroprom e a Lianozovo.

Apesar da produção de Kefir, em alguns países, acontecer em escala comercial, a maioria das indústrias utilizam apenas algumas amostras bacterianas isoladas dos grãos de Kefir para a produção da bebida, fazendo com que muitas das propriedades naturais encontradas no Kefir de produção caseira não sejam encontrados nos produtos comercializados (Weschenfelder, 2009)

Segundo Gonçalves et al. (2018) muitos são os ganhos associados ao consumo regular e constante de kefir. Entre eles a supressão de tumores, atividade antimicrobiana, inibição da enzima conversora de angiotensina (ECA), aumento da velocidade de cicatrização de feridas, melhora na resposta do sistema imune, como alergia e asma. Logo Santos et al (2020), comentam a necessidade de haver um incentivo ao consumo regular de Kefir, uma vez que proporciona vantagens à saúde.

Por esses motivos, o presente trabalho tem como objetivo avaliar o desenvolvimento de um novo produto à base de kefir e analisar suas características microbiológicas, físico-química.

\section{Revisão Bibliográfica}

\subsection{Kefir}

O Kefir difere de outros leites fermentados porque é resultado metabólico de diferentes tipos de micro-organismos. Estudos apontam que a maior parte da população microbiana é composta por lactobacilos, entretanto, não se conhece a composição total dos grãos de Kefir. Isso se deve ao fato de a composição microbiana variar conforme a região de origem do grão, características físico-químicas do substrato, técnicas de produção e tempo de fermentação (Santos et al., 2012).

Segundo Paiva (2013), os grãos de Kefir são capazes de fermentar em diversos substratos, como leite de diferentes espécies, leite de soja, coco, arroz, soro de queijo, cacau, açúcar mascavo, extrato de soja, suco de frutas, dentre outros. O preparo da bebida fermentada se dá diretamente pela incorporação dos grãos no substrato de preferência. Entretanto, o sabor e o aroma do Kefir são resultados diretos da atividade metabólica simbiótica das bactérias e das leveduras que se encontram naturalmente nos grãos. Atualmente, dois tipos de Kefir são conhecidos: de água e de leite bovina (Santos et al., 2012).

Os grãos de Kefir são massas irregulares gelatinosas, que apresentam coloração amarelada ou esbranquiçada, seu diâmetro varia de 3 a 35mm (Santos et al., 2012), nas quais são constituídas por bactérias ácido-acéticas, lácticas e leveduras imersas em uma matriz de polissacarídeos e proteínas (Dias et al., 2018). A diversidade na microbiota dos grãos é extensa, apresentando uma heterogeneidade, variando de acordo com os métodos de cultivo. Segundo Paiva (2013) os principais microorganismos comumente isolados são do gênero Lactococcus, Lactobacillus, Leuconostoc, Enterococcus e Streptococcus, bactérias ácidos-acéticas Acetobacter e leveduras Saccharomyces, Kluyveromyces e Candida.

A matriz do grão é constituída por $13 \%$ do complexo de proteína, $24 \%$ de polissacarídeo, detritos celulares e componentes desconhecidos. Sua matriz polissacarídica é constituída em sua maior parte por exopolissacarídeos (EPS), que são polímeros constituídos por centenas ou milhares de resíduos monossacarídeos que podem ser produzidos por algumas cepas de algas, bactérias, fungos e leveduras, proporcionando um balanço microbiológico relativamente estável. Os EPS auxiliam para evitar o estresse osmótico, fagocitose, dessecação celular e predação de protozoários (Paiva, 2013). O principal polissacarídeo, encontrado na matriz dos grãos, é um componente hidrossolúvel denominado kefiran. De acordo com Alemida (2018) sua composição físico-química ainda é estudada, visto que pode variar conforme a idade dos grãos, a microbiota, o substrato de utilização e a tecnologia utilizada no processamento. Porém já se conhece que o componente hidrossolúvel é composto por quantidades iguais de D-glicose e D-galactose (TERRA, 2007). 
Segundo Almeida (2018), estudos descrevem que a matriz dos grãos de Kefir são constituídas por 86,3\% de umidade, 4,5\% de proteína, $1,2 \%$ de cinzas e $0,03 \%$ de gordura. Entretanto, a composição da bebida fermentada de Kefir é de $89-90 \%$ de umidade, $0,2 \%$ de lipídios, 3,0\% de proteína, 6,0\% de açúcar, $0,7 \%$ de cinzas e 1,0\% de ácido láctico e de álcool.

Para Santos et al. (2012), a produção do Kefir de água e de leite é semelhante. O método tradicional da produção da bebida consiste pela inserção de 5\% dos grãos de Kefir no substrato de preferência, conforme sugerido por Almeida (2018). O substrato, leite ou água, com açúcar mascavo devem ser pasteurizados ou fervidos e depois resfriados a temperatura ambiente para inoculação dos grãos. Por exemplo, 50 gramas de grãos são adicionados em um litro do substrato contendo 50 gramas de açúcar mascavo. Durante o início da fermentação dos grãos de Kefir, ocorre um aumento inicial no tamanho destes que, posteriormente, se subdividem em novos grãos, mantendo o equilíbrio microbiológico presente nos grãos originais. A média do crescimento diário dos grãos é de 5\% e 45\%, respectivamente para grãos de leite e de água. Essa média de crescimento varia conforme alguns fatores, como: a prensagem dos grãos durante a peneiragem e agitação periódica do frasco com o fermentado.

Após o período de fermentação, que varia de 18 a 24 horas, em temperatura ambiente, coa-se a mistura retirando os grãos para a nova fermentação (Terra, 2007), posteriormente, são utilizados para inoculação em um novo substrato. O filtrado que foi submetido à fermentação lática é armazenado na geladeira, permanecendo por 24 horas, nesta fase, as leveduras produzirão álcool e $\mathrm{CO}_{2}$ tornando o produto mais refrescante. Após a etapa de maturação, o kefir estará pronto para o consumo, podendo em seguida ser adicionado, ou não, de sucos e pedaços de frutas para seu consumo (SANTOS et al., 2012).

A partir da produção do Kefir pode se obter 2 produtos: leban e o soro de Kefir. A fase sólida obtida da filtração do Kefir é conhecida como leban que é facilmente digerido, com sabor e textura similar ao do queijo quark, pode ser consumido tanto in natura quanto em substituições de formulações, como a substituição do cream cheese. O soro do Kefir consiste no líquido retirado da filtração da fermentação, podendo ser utilizado como matéria prima para a produção de bebidas lácteas até a produção de produtos mais específicos (Weschenfelder, 2009).

\subsection{Alimentos nutracêuticos}

O termo nutracêutico se refere a um alimento/ingrediente alimentar que promove benefícios a saúde, podendo servir de tratamento preventivo e de doenças pré-existentes (Oliveira et al., 2002). As propriedades nutracêuticas são encontradas em suplementos dietéticos encapsulados, como nutrientes isolados, até produtos beneficamente projetados, ou ultra-processados como bebidas e sopas (Moraes et al., 2006). Desta forma, o alimento com características nutracêuticas pode ser considerado um alimento funcional.

O alimento funcional deve cumprir, além da sua função básica de nutrir, proporcionar um ou mais benefícios sobre as funções alvo do organismo do consumidor (Almeida, 2018). Para que o potencial benéfico destes alimentos seja alcançado é necessário o consumo regular na dieta diária (Paiva, 2013), como o consumo de alimentos probióticos (Matta et al, 2009). Deve ser evidenciado também que seu benefício está relacionado somente à promoção da saúde e não à cura de doenças (Oliveira et al., 2002). Ainda sobre os benefícios do consumo de kefir Terra (2007) comentam que existe boa aceitação do Kefir com os intolerantes à lactose, é devido à presença de $\beta$-galactosidase no filtrado de Kefir, que auxilia na digestão da lactose no trato gastrointestinal.

Atualmente, tem-se conhecimento da alta complexidade do ecossistema da microbiota intestinal, que compreende cerca de 100 trilhões de bactérias distribuídas em mais de 400 espécies. A microbiota intestinal, de forma harmônica e estável, abriga bactérias benéficas e patogênicas em indivíduos saudáveis, entretanto, diversos fatores podem ser responsáveis por causar alterações nesse ecossistema, como: dieta, envelhecimento, estado fisiológico, doenças, estresse, uso de antibióticos, drogas e quimioterápicos, dentre outros fatores (Santos et al., 2012). 
A Organização Mundial da Saúde (OMS) define o termo probióticos, proposto por R. Fuller em 1989, como "microorganismos vivos que, quando administrados em quantidades adequadas, conferem benefícios à saúde do hospedeiro". São substâncias inativadas, que intervêm como suplementos de energia para as bactérias benéficas, sendo algumas cepas utilizadas em produtos com propriedades probióticas (Almeida, 2018).

\subsection{Probiótico}

Segundo Coppola et al. (2004), ainda não se conhece completamente o modo de ação dos probióticos, apesar de se saber que alguns processos podem atuar de forma independente ou associado. Um dos processos sugeridos é o de exclusão competitiva, em que os patógenos competiriam com os probióticos por nutrientes e sítios de fixação, impedindo a ação transitória dos patógenos.

Os probióticos influenciam de forma benéfica a microbiota intestinal, visto que sofrem alguns efeitos imunológicos, antagônicos e de competição, estimulando o aumento da resistência contra patógenos (Weschenfelder, 2009).

Além disso, os probióticos alteram o ecossistema intestinal de forma a aumentar a população de bactérias anaeróbias benéficas e diminuir a população de micro-organismos potencialmente patogênicos. Estudos demonstram que o consumo dos probióticos devem ser parte da dieta diária, uma vez que esses não colonizam o intestino e desaparecem do trato gastro intestinal (TGI) quando o consumo é interrompido (Almeida, 2018).

Como o Kefir é considerado um probiótico, seu consumo regular traz diversos benefícios, tais como atividade antimicrobiana contra patógenos, estimulação do sistema imune, equilíbrio da microbiota intestinal e ação antitumoral. Além disso, o Kefir pode ser considerado uma alternativa para a inibição do desenvolvimento bacteriano indesejável, visto que possui propriedade antimicrobiana, agindo dessa forma como conservante natural (Santos et al., 2012).

Segundo Dias et al. (2016), o Kefir, constitui uma alternativa viável na busca de substitutos para os antimicrobianos convencionais, por meio dos microrganismos que o compõem e das substâncias bioativas por eles produzidas. Vários estudos vêm demonstrando o uso potencial de microrganismos isolados, dos grãos de Kefir, frente a patógenos de origem alimentar. Entretanto, seus mecanismos de ação ainda são pouco conhecidos.

\subsection{Propriedades nutricionais do Kefir}

Quanto as propriedades nutricionais, o Kefir possui diversos compostos como vitaminas do complexo B, minerais e aminoácidos essenciais, como triptofano, precursor do neurotransmissor serotonina, imprescindíveis para a manutenção de funções vitais do ser humano. Possui também proteínas que são parcialmente digeridas e facilmente utilizadas pelo organismo (Almeida, 2018).

As características benéficas do Kefir na saúde não estão apenas ligadas à sua microflora. Entre os benefícios destacase a atividade microbiana contra bactérias Gram-positivas e negativas. Além do tratamento clínico de doenças gastrointestinais, metabólicas, cardíacas, isquêmicas, redução do risco de doenças crônicas e alergias. Possui também propriedades antiinflamatórias, antitumorais, antioxidantes e imunomoduladoras. Podendo auxiliar também na regulação e atuação renal e hepática, melhorando a cicatrização e o sistema imune (Gonçalves et al., 2018).

Segundo Weschenfelder (2009) não se sabe a origem evolutiva dos grãos de Kefir. Apesar de se conhecer a constituição da matriz dos grãos Kefir, não foi encontrada sua formação espontânea em laboratório. Novos grãos de Kefir se originam somente da multiplicação e repartição de grãos de Kefir pré-existentes. São considerados por estudiosos como uma comunidade que coexiste em uma relação de simbiose (Paiva, 2013).

A fermentação lática e alcoólica do filtrado de Kefir o torna mais nutritivo, pois proporciona o aumento da biodisponibilidade dos seus componentes. Durante o processo ocorre a quebra das proteínas do leite que são desdobradas para 
peptídeos menores, promovendo o acúmulo de aminoácidos. Além disso, a bebida se torna de fácil digestão se comparada com a matéria prima (leite) devido a hidrolise parcial da proteína (Santos et al., 2012).

Durante a dupla fermentação, ocorre a produção de pequenas quantidades de álcool, dióxido de carbono e moléculas aromáticas que são responsáveis pela produção de sabor e aroma característico (Weschenfelder 2009), além de possuir compostos bioativos, responsáveis por propriedades nutracêuticas (Dias et al., 2018).

\subsection{Produtos alimentícios a base de Kefir}

A indústria alimentícia vem se adequando a nova tendência de produzir leite, leite fermentado e iogurte funcionais. Esse segmento da indústria alimentícia quer aumentar sua competitividade com o segmento de produtos funcionais e probióticos, se adaptando ao mercado consumidor cada vez mais exigente (Santos, 2012).

Segundo Santos (2012), diferentemente do Brasil o mercado internacional já produz em escala industrial produtos alimentícios oriundos da fermentação dos grãos de Kefir. A empresa DMJ Biotech Corp. situada na Coreia do Sul possui uma vasta variedade de produtos utilizando grãos de Kefir, como requeijão cremoso, queijo, leites, Kefir de diversos sabores entre outros.

Os fabricantes vêm tentado suprir um nicho de mercado explorando novas opções de sabores para iogurtes e leites fermentados. Uma grande alternativa para agregar características sensoriais ao leite fermentado de Kefir é a adição de diferentes tipos de frutas, visto que o kefir possui um sabor marcante e característico, que comparado com o iogurte natural tradicional é mais forte ao paladar, diminuindo sua aceitabilidade em algumas preparações (Silva, 2019).

Foi desenvolvido em Governador Mangabeira-BA, pela Faculdade Maria Milza - FAMAM, um iogurte de Kefir com geleia de banana da prata. Rica em minerais como ferro, cálcio, manganês, potássio e cobre, além de vitaminas A,C, B3, B6 entre outras. Após realização de teste sensorial com o objetivo de conferir a aceitabilidade do produto, o mesmo conseguiu receber elevados índices de aceitabilidade dos provadores nos quesitos de cor, aroma, textura e impressão geral (Silva, 2019).

Diante do cenário consumidor atual e dos benefícios associados ao consumo do Kefir, vem aumentando a busca pelo desenvolvimento de novas formulações oriundas do Kefir. Além disso, a utilização, desenvolvimento e perfil sensorial de produtos com Kefir ainda são insuficientes na literatura (MACHADO, 2019).

\section{Materiais e Métodos}

A metodologia deste trabalho foi caracterizada como um estudo de natureza qualitativa e quantitativa, onde a parte qualitativa é correspondente as análises microbiológicas enquanto a parte quantitativa está relacionada ao estudo físico químico.

\section{A) Produção artesanal do manjar de ameixa com coco}

Pesou-se 40 gramas de grãos de kefir e adicionou em três litros de leite pasteurizado. Após o período de fermentação, que variou, de 24 horas, em temperatura ambiente, os grãos foram separados da bebida fermentada por filtração, com uma peneira, e, posteriormente, estes foram utilizados para inoculação em um novo substrato.

O filtrado que foi submetido à fermentação lática foi transferido para a geladeira, permanecendo por 6 horas. Nesta fase, as leveduras estarão produzir o álcool e $\mathrm{CO}_{2}$, tornando o produto mais refrescante. Após a etapa de maturação, o Kefir ficou pronto para o consumo.

Em seguida, adicionou-se xilitol e essência de baunilha, e bateu em batedeira para ganhar forma. Uma vez pronta a base do Manjar de Kefir, foi saborizada com leite de coco, coco ralado e uma pasta de ameixa preta (Figura 1). 
Figura 1. Manjar de ameixa com coco elaborado com Kefir.

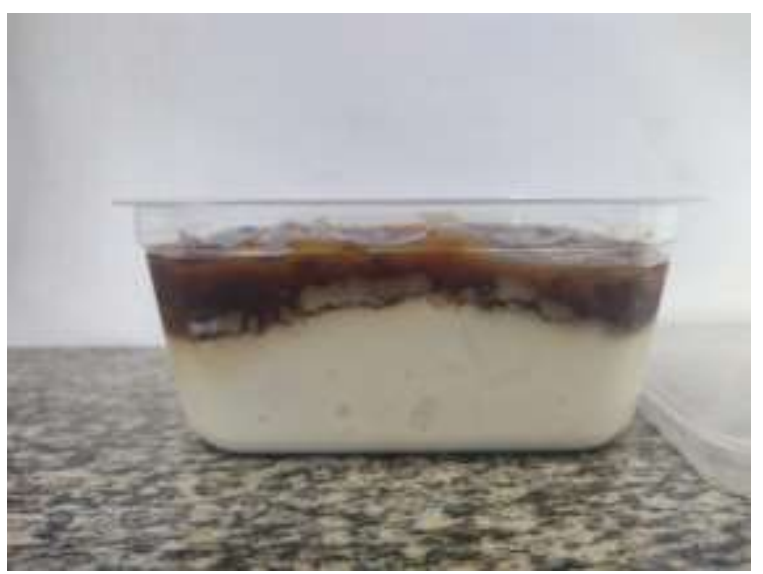

Fonte: Autores (2021).

\section{B) Análise de shelf life}

\section{B1) Testes microbiológicos}

Foram realizados testes microbiológicos de coliformes a $35^{\circ} \mathrm{C}$, coliformes a $45^{\circ} \mathrm{C}$ e Salmonella sp, em duplicada, nos tempos de coleta: $0,3,6$ e 9 dias.

- Coliformes a $35^{\circ} \mathrm{C}$ e coliformes a $45^{\circ} \mathrm{C}$

Foram pesado $25 \mathrm{~g}$ da amostra do manjar em um Erlenmeyer contendo $225 \mathrm{ml}$ de água peptonada, considerando esta diluição $10^{-1}$. Em seguida pipetou-se $1 \mathrm{ml}$ da diluição $10^{-1}$ para um tubo contendo $9 \mathrm{ml}$ de água peptonada, considerando esta como a diluição $10^{-2}$ e pipetou-se $1 \mathrm{ml}$ da diluição $10^{-2}$ para um tubo contendo $9 \mathrm{ml}$ de água peptonada, considerando esta como a diluição $10^{-3}$.

Após a diluição pipetou $1 \mathrm{ml}$ de cada diluição em tubo contendo $9 \mathrm{ml}$ de Lauril sulfato triptose (LST) e incubou as amostras a $37^{\circ} \mathrm{C}$ por 24 a 48 horas, para verificar a presença de coliformes a $35^{\circ} \mathrm{C}$. Foram transferidos com uma alça de repicagem do tubo LST positivo para o tubo contendo Verde Bile Brilhante (VB) e incubou os tubos a $37^{\circ} \mathrm{C}$ por 24 a 48 horas para a confirmação dos coliformes a $37^{\circ} \mathrm{C}$ e para a confirmação de coliformes a $45^{\circ} \mathrm{C}$ foram transferidos do tubo LST positivo com uma alça de repicagem para tubos contendo EC médium (EC) e incubou estes tubos por 24 a 48 horas a $45^{\circ} \mathrm{C}$ (Silva et al, 2007).

\section{- $\quad$ Salmonella sp}

Para análise de Salmonella spp. pesou-se $25 \mathrm{~g}$ da amostra em $225 \mathrm{~mL}$ de água peptonada a $1 \%$ e foram incubadas a $37^{\circ} \mathrm{C}$ por 24 horas. As amostras foram transferidas para dois diferentes caldos de enriquecimento seletivo, RappaportVassiliadis e Tetrationato-Novobiocina e os tubos foram incubados a 37 e $42^{\circ} \mathrm{C}$ respectivamente por 24 horas. Os tubos foram semeados em Ágar Verde Brilhante (VB) e em Ágar Hektoen (HE) e incubados por 24 horas a $37^{\circ} \mathrm{C}$, para verificação de possível crescimento de colônias típicas da Salmonella (Silva et al, 2007).

\section{- Contagem de lactobacilos}

Foram pesados $25 \mathrm{~g}$ da amostra do manjar em um Erlenmeyer contendo $225 \mathrm{ml}$ de água peptonada, considerando esta diluição $10^{-1}$. Em seguida pipetou $1 \mathrm{ml}$ da diluição $10^{-1}$ para um tubo contendo $9 \mathrm{ml}$ de água peptonada, considerando esta 
como a diluição $10^{-2}$ e pipetou $1 \mathrm{ml}$ da diluição $10^{-2}$ para um tubo contendo $9 \mathrm{ml}$ de água peptonada, considerando esta como a diluição $10^{-3}$.

Em seguida pipetou 0,1 $\mathrm{ml}$ de cada diluição e distribuiu no meio de cultura MRS e distribuiu a amostra com a alça de Drigalsky esterilizado. Após a distribuição do inóculo, foi acrescentado aproximadamente $20 \mathrm{ml}$ do meio MRS e incubou as placas a $37^{\circ} \mathrm{C}$ por 48 horas em jarra de anaerobiose (Silva et al, 2007).

- Bolores e leveduras

Foram pesados $25 \mathrm{~g}$ da amostra do manjar em um Erlenmeyer contendo $225 \mathrm{ml}$ de água peptonada, considerando esta diluição $10^{-1}$. Em seguida pipetou $1 \mathrm{ml}$ da diluição $10^{-1}$ para um tubo contendo $9 \mathrm{ml}$ de água peptonada, considerando esta como a diluição $10^{-2}$ e pipetou $1 \mathrm{ml}$ da diluição $10^{-2}$ para um tubo contendo $9 \mathrm{ml}$ de água peptonada, considerando esta como a diluição $10^{-3}$.

Em seguida pipetou $0,1 \mathrm{ml}$ de cada diluição e distribuiu meio de cultura PDA e distribuiu a amostra com a alça de Drigalsky esterilizado e incubou as placas a $25^{\circ} \mathrm{C}$ por 5 dias (Silva et al, 2007).

\section{B2) Análise físico-químico}

Para os testes físico-químicos realizados foram realizados os: $\mathrm{pH},{ }^{\circ}$ Brix, acidez titulável e atividade de água. As análises foram realizadas nos dias: $0,3,6 \mathrm{e} 9$. Todos em triplicata.

- pH: A determinação de pH foi realizada com um pHmetro. Foi mergulhado o eletrodo calibrado na amostra, coletando os dados em triplicata.

- ${ }^{\circ}$ Brix: Foi determinado o ${ }^{\circ}$ Brix do produto utilizando um refratômetro ${ }^{\circ}$ Brix em escala numérica de índice de refração de uma solução.

- Acidez titulável: Para a determinação da Acidez do Manjar de ameixa com coco, foi utilizado o método 493/IV conforme consta na literatura de Adolfo Lutz (Brasil, 2005). Pesou-se aproximadamente $10 \mathrm{~g}$ da amostra em um béquer de $50 \mathrm{~mL}$. Adicionou com pipeta graduada aproximadamente $10 \mathrm{~mL}$ de água, isenta de gás carbônico, e misturou com bastão de vidro. Adicionou 5 gotas da solução de fenolftaleína. Em seguida titulou com solução de hidróxido de sódio $0,1 \mathrm{M}$ até o aparecimento de uma coloração rósea. Para o cálculo usou-se a Equação 1.

Cálculos:

V x F x 0,9/P=g de ácido lático por cento (Equação 1).

Onde: $\mathrm{V}=\mathrm{n}^{\circ}$ de $\mathrm{mL}$ de solução de hidróxido de sódio $0,1 \mathrm{M}$ gasto na titulação $\mathrm{P}=\mathrm{n}^{\circ} \mathrm{g}$ ou $\mathrm{mL}$ da amostra $0,9=$ fator de conversão para o ácido láctico f = fator da solução de hidróxido de sódio $0,1 \mathrm{M}$.

\section{B3) Análise físico química complementares}

As análises complementares realizadas neste trabalho foram: Teor de Gordura, Cálcio, Carboidratos, Lactose e sólidos totais.

- Teor de Gordura: Para a determinação do teor de Gordura no produto, foi utilizado o método 496/IV conforme consta na literatura do Adolfo Lutz (Brasil, 2005). Pesou 5g da amostra, em béquer de $100 \mathrm{~mL}$. Foi transferida para um béquer 100 $\mathrm{mL}$ de água, e quando foi necessário, utilizou água à temperatura entre (30-40) ${ }^{\circ} \mathrm{C}$. Adicionou $60 \mathrm{~mL}$ de ácido clorídrico. Foi aquecido o conjunto na chapa aquecedora até a fervura, mantendo a fervura durante 30 minutos. À parte, foi aquecido aproximadamente $1000 \mathrm{~mL}$ de água até temperatura de (90-95) ${ }^{\circ} \mathrm{C}$, adicionou $100 \mathrm{~mL}$ desta água na solução da amostra 
ainda quente, lavando o vidro de relógio e foi filtrado em papel de filtro previamente umedecido. Lavou várias vezes o béquer e o resíduo do papel de filtro, cuidadosamente, com água quente até que o filtrado exibisse reação neutra, (utilizando fita indicadora de $\mathrm{pH}$ ). Colocou o resíduo sobre um vidro de relógio, contendo um papel de filtro seco, secou na estufa à temperatura de $(103 \pm 2){ }^{\circ} \mathrm{C}$. Envolveu em outro papel de filtro ou colocou em um dedal e transferiu para o aparelho extrator de Soxhlet. Foi acoplado um balão de fundo chato de $300 \mathrm{~mL}$ previamente aquecido em estufa a $(103 \pm 2)$ ${ }^{\circ} \mathrm{C}$ por duas horas, resfriado e pesado ao aparelho extrator de Soxhlet. Foi extraído sob aquecimento, com aproximadamente $250 \mathrm{~mL}$ de éter de petróleo durante 4 horas. Retirou o resíduo da extração e removeu o solvente por destilação. Secou-se o balão contendo a gordura em estufa a $(103 \pm 2){ }^{\circ} \mathrm{C}$ por uma hora. Resfriou em dessecador e foi pesado. A amostra foi retornada à estufa por 30 minutos, resfriada em dessecador e pesada. Foi repetida as operações de aquecimento e resfriamento até peso constante. Para o cálculo do teor de gordura, utilizou-se a Equação 2.

Cálculos:

100x $\mathrm{N} / \mathrm{P}=\mathrm{g}$ de gordura por cento $\mathrm{m} / \mathrm{m}$

(Equação 2).

$\mathrm{N}=\mathrm{n}^{\circ}$ de $\mathrm{g}$ de gordura $\mathrm{P}=\mathrm{n}^{\circ}$ de gramas da amostra

- Determinação de Cálcio: Para a determinação do Teor de Cálcio foi utilizado o método 396/IV conforme consta na literatura do Adolfo Lutz (Brasil, 2005). Baseada na mineralização da amostra e determinação de cálcio por titulação complexométrica com EDTA (sal dissódico do ácido etilenodiamino tetracético), foi usado uma mistura de ácido calconcarboxílico, alaranjado de metila e cloreto de sódio, como indicador. Pipetou, em um frasco Erlenmeyer, uma alíquota da solução da amostra previamente mineralizada que contendo cerca de $5 \mathrm{mg}$ de cálcio e adicionou $50 \mathrm{~mL}$ de água. Ajustou o pH da solução para a faixa de pH de (12-14), adicionando pastilhas de hidróxido de sódio. Adicionou a mistura do indicador até que a solução adquirisse a coloração vinho. Titulou com a solução de EDTA 0,01 M, utilizando agitador magnético, até que a coloração da solução da amostra alterasse para cor verde persistente. Titulou um branco preparando da mesma forma, com todos os reagentes utilizados na amostra. Calculou a concentração de cálcio, usando a fórmula a seguir (Equação 3).

\section{Cálculos:}

40x(VA-vB)x vb x M x 100/va x 100= mg de cálcio por cento (Equação 3)

$\mathrm{VA}=$ volume de EDTA gasto na tilulação da amostra, em $\mathrm{mL} \mathrm{VB}=$ volume de EDTA gasto na titulação do branco, em $\mathrm{mL} \mathrm{Vb}=$ volume do balão volumétrico para o qual a amostra foi transferida, em $\mathrm{mL} \mathrm{Va}=$ alíquota da amostra usada na titulação, em $\mathrm{mL}$ e $\mathrm{m}=$ massa da amostra, em $\mathrm{g} \mathrm{M}=$ molaridade do EDTA.

- Teor de Lactose: Foi utilizado o método 499/IV conforme consta na literatura do Instituto Adolfo Lutz (Brasil, 2005). Pesou aproximadamente $5 \mathrm{~g}$ da amostra em béquer de $100 \mathrm{~mL}$. Transferiu quantitativamente com auxílio de $50 \mathrm{~mL}$ de água e um bastão de vidro para um balão volumétrico de $100 \mathrm{~mL}$. Adicionou $2 \mathrm{~mL}$ da solução de sulfato de zinco a $30 \%$, adicionou $2 \mathrm{~mL}$ da solução de ferrocianeto de potássio a 15\%. Deixou sedimentar, durante 5 minutos, completou o volume do balão com água e agite. Filtrou em papel de filtro para um frasco Erlenmeyer de $300 \mathrm{~mL}$. Em balão de fundo chato adicionou $10 \mathrm{~mL}$ de cada uma das soluções de Fehling, $40 \mathrm{~mL}$ de água e aqueceu até ebulição. Transferiu o filtrado para uma bureta e adicionou sobre a solução do balão em ebulição, agitando sempre, até que esta solução virasse da cor azul para o incolor. 
Cálculo:
A x $0,058 \times 100 / \mathrm{Vx} \mathrm{P}=$ lactose por cento $\mathrm{m} / \mathrm{m}$
(Equação 4).

$\mathrm{A}=\mathrm{n}^{\circ}$ de $\mathrm{mL}$ de $\mathrm{Pg}$ da amostra $\mathrm{V}=\mathrm{n}^{\circ}$ de $\mathrm{mL}$ da solução da amostra gasto na titulação $\mathrm{P}=\mathrm{n}^{\circ}$ de $\mathrm{g}$ da amostra

- Sólidos totais: Foi utilizado o método 202/IV conforme consta na literatura de Adolfo Lutz (Brasil, 2005). Aqueceu, em uma estufa, uma cápsula limpa de porcelana a $(103 / 105){ }^{\circ} \mathrm{C}$, por no mínimo 3 horas. Retirou da estufa, transferindo para um dessecador, até a temperatura ambiente e foi pesado. Mediu $100 \mathrm{~mL}$ da amostra de água não filtrada em um balão volumétrico e transferiu quantitativamente para a cápsula já pesada. Evaporou até secagem em uma chapa de aquecimento. Colocou a cápsula em uma estufa a $105^{\circ} \mathrm{C}$ por 3 horas. Transferiu a cápsula para um dessecador, deixando atingir o equilíbrio térmico com o ambiente e pesou. Repetiu as operações até obter peso constante (Equação 5). As determinações foram feitas em duplicata.

Cálculos:

(A-B)/V= mg de sólidos totais por litro

(Equação 5)

$\mathrm{A}$ = massa (resíduo seco + cápsula) mg B = massa da cápsula mg v = volume da amostra em L.

\section{Resultados e Discussão}

$\mathrm{Na}$ análise microbiológica (Tabela 1), foi possível observar que a contagem de coliformes e Salmonella se encontraram dentro do limite aceito pela legislação vigente para produtos lácteos fermentados durante os nove dias de coleta.

$\mathrm{O}$ valor de coliformes $37^{\circ} \mathrm{C}$ e a $45^{\circ} \mathrm{C}$ não foram encontrados durante os nove dias de análise no experimento, assim os resultados indicam que a produção foi em condições higiênicas satisfatórios, uma vez que, segundo Cardoso et al. (2001), a presença de coliformes a $37^{\circ} \mathrm{C}$ e a $45^{\circ} \mathrm{C}$ indicam as condições higiênicos sanitárias inadequadas na produção do produto.

As amostras apresentaram uma quantidade de leveduras superior ao estipulado pela legislação para leites fermentados,

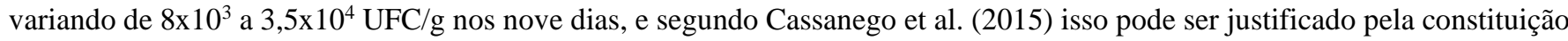
dos grânulos de Kefir apresentar uma relação de simbiose entre as bactérias e leveduras. Já Ribeiro (2015), comenta que o filtrado de Kefir deve apresentar presença de bactérias láticas totais de no mínimo de $10^{7}$ UFC/g e de leveduras de no mínimo de $10^{4} \mathrm{UFC} / \mathrm{g}$, logo nossos resultados estão dentro dos valores esperado.

Tabela 1. Resultados das análises microbiológicas das amostras de manjar de coco com ameixa nos nove dias de coleta.

\begin{tabular}{cccccc}
\hline Tempo (dia) & $\begin{array}{c}\text { Coliformes } \\
37^{\circ} \mathrm{C}\end{array}$ & $\begin{array}{c}\text { Coliformes } \\
45^{\circ} \mathrm{C}\end{array}$ & $\begin{array}{c}\text { Bolor e } \\
\text { Leveduras }\end{array}$ & Lactobacilos & Salmonella \\
\hline 0 & $<3$ & $<3$ & $8,0 \times 10^{3}$ & $1,5 \times 10^{3}$ & Ausência \\
3 & $<3$ & $<3$ & $5,2 \times 10^{3}$ & $2,5 \times 10$ & Ausência \\
6 & $<3$ & $<3$ & $2,3 \times 10^{3}$ & $<10$ & Ausência \\
9 & $<3$ & $<3$ & $3,5 \times 10^{4}$ & $<10$ & Ausência \\
\hline
\end{tabular}

Fonte: Autores (2021).

A ausência da Salmonella nas amostras foi compatível com os resultados de Dias et al. (2016), que comprovam que após um período de fermentação de 24 horas não foi possível encontrar bactérias ativas de Salmonella Typhimurium e 
Salmonella Enteritidis. Isso porque o ambiente se torna desfavorável devido a fermentação, uma vez ocorre a produção de ácidos acéticos, láticos e orgânicos, que contribuem para acidificação do meio, tornando-o hostil para boa parte dos microorganismos.

Em relação a contagem de lactobacilos encontrado no manjar, foi possível observar a diminuição da concentração com o passar dos dias, Contim e colaborares (2018) também observaram a diminuição da contagem de lactobacilos com o tempo. Isso pode ser justificado pela diminuição do substrato disponível no meio e o aumento da acidez. Desta forma, sob o ponto de vista microbiológico, o manjar de ameixa com coco elaborado com Kefir se encontrou viável para consumo durante os nove dias de armazenamento sob refrigeração.

A partir da realização das análises físico-químicas observou que o no tempo zero (T0) apresentou pH 4,21 com acidez de 1,095 \pm 0,0013 e com o tempo foi acidificando para pH 4,16 com acidez titulável de 1,185 $\pm 0,0050$ (Tabela 2). Estes valores se encontram dentro da legislação brasileiras que estabelecem um limite de ácido lático para leites fermentados de Kefir, entre 0,5 e 1,5g de ácido lático em 100g de fermentado (Brasil, 2007). Ainda de acordo com Almeida (2018), estudos sugerem que para o desenvolvimento de um produto viscoso e de baixa acidez, a melhor concentração é de $10 \mathrm{~g} / \mathrm{L}$ de grãos de Kefir. Entretanto para a produção de uma bebida ácida, com baixa viscosidade e mais efervescente, a concentração mais indicada é de $100 \mathrm{~g} / \mathrm{L}$. Com base nesses dois produtos, a proporção $5 \%$ provou ser mais adequada para produção de etanol e ácidos voláteis.

Segundo Parreiras et al. (2019), o valor de $\mathrm{pH}$ encontrado para o fermentado de Kefir a 5\% foi de 5,13 $\pm 0,06$ e uma acidez titulável de 0,60 $\pm 0,08$, isso implica que o manjar de ameixa com coco apresenta menor $\mathrm{pH}$ e uma maior acidez titulável provavelmente por ter uma quantidade de Kefir inferior ao utilizado por Parreiras e colaboradores, o que pode ser justificado pela maior acidez nos grânulos de Kefir utilizados para a produção de manjar (Tabela 2).

Terra (2007), trabalhou com fermentado de Kefir a 8\% com uma fermentação de 24 horas e obteve um pH de 3,9 e acidez de 1,14, esse valor foi mais próximo com o encontrado no manjar do nosso trabalho. Entretanto, deve-se observar que Terra (2007) produziu um fermentado mais concentrado, o que deveria impactar em um menor $\mathrm{pH}$ e maior acidez, isso reafirma a teoria de que os grãos utilizados para a produção do manjar poderiam apresentar uma maior acidez.

Montanuci et al. (2018) que analisou fermentado de Kefir a $1 \%$ encontraram ${ }^{\circ}$ Brix de 9,22 $\pm 0,19$. Já Costa et al. (2018), analisaram bebida látea fermentada com Kefir a 5\% enriquecida com amora-preta encontraram ${ }^{\circ}$ Brix de 6,42 $\pm 0,23 \mathrm{e}$ para fermentado de Kefir a $20 \%$ encontraram ${ }^{\circ}$ Brix de 12,17 $\pm 0,11$. Esse valor difere do manjar com ameixa, entretanto, notase que com a adição de polpa de ameixa incide no aumento do ${ }^{\circ}$ Brix. Esses valores diferem do nosso resultado (Tabela 2), isso porque, durante o preparo foram utilizados calda de ameixa, leite de coco e coco ralado que são ingredientes que realçam o sabor, mas elevaram o ${ }^{\circ}$ Brix. 
Research, Society and Development, v. 10, n. 10, e154101018543, 2021

(CC BY 4.0) | ISSN 2525-3409 | DOI: http://dx.doi.org/10.33448/rsd-v10i10.18543

Tabela 2. Resultados dos dados das análises físico-químicas do manjar de coco com ameixa nos nove dias de coleta.

\begin{tabular}{cccc}
\hline $\begin{array}{c}\text { Tempo } \\
\text { (dia) }\end{array}$ & $\mathrm{Ph}$ & ${ }^{\circ}$ Brix & Acidez $(\%)$ \\
\hline 0 & $4,21 \pm 0,022$ & $24,67 \pm 0,47$ & $1,095 \pm 0,0013$ \\
3 & $4,19 \pm 0,022$ & $23,67 \pm 0,47$ & $1,117 \pm 0,0075$ \\
6 & $4,12 \pm 0,010$ & $23,33 \pm 0,47$ & $1,165 \pm 0,0050$ \\
9 & $4,16 \pm 0,0051$ & $21,67 \pm 0,47$ & $1,185 \pm 0,0050$ \\
\hline
\end{tabular}

Fonte: Autores (2021).

Analisando o desvio padrão do pH (Figura 2), percebeu que há uma queda no valor de pH, onde o valor máximo encontrado foi de 4,21 e o valor mais baixo de 4,12. Isso porque, segundo Villanoeva (2016) a diminuição do pH ocorre devido a produção de ácidos orgânicos, etanol, gás carbônico e outros compostos voláteis.

Percebe-se que com o período de análise ocorre a diminuição do pH conforme o tempo de estocagem do produto, isso pode ser justificado pela presença de lactobacilos na formulação, que ainda estão realizando fermentação ácido-lática, promovendo a diminuição do $\mathrm{pH}$.

Figura 2. Avaliação do pH por tempo (dia).

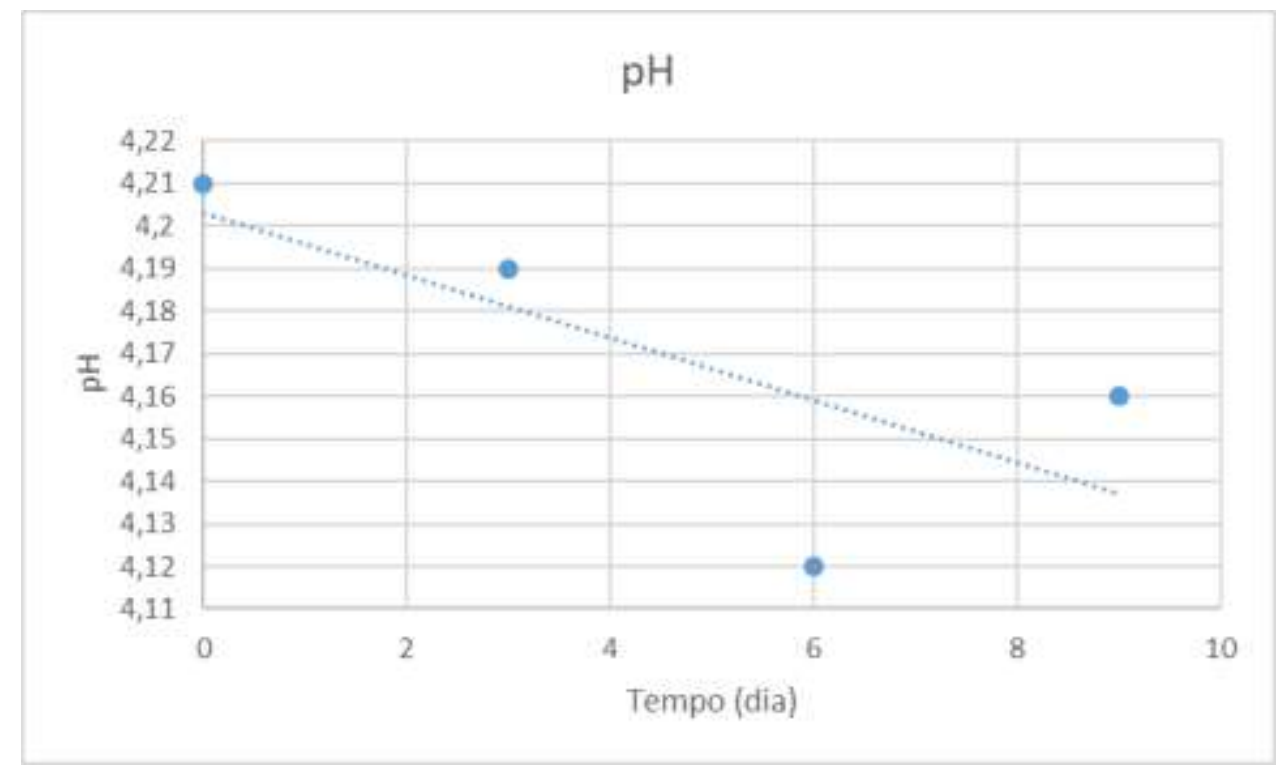

Fonte: Autores (2021).

Observou-se que no desvio padrão da acidez (Figura 3) houve um aumento conforme o tempo de estocagem, essa característica de curva ocorre também devido a presença de lactobacilos na formulação, que ainda estão realizando fermentação ácido-lática, o que eleva a o teor de acidez. Segundo Araújo et al. (2020), quanto maior o tempo de fermentação maior será a acidez. 
Figura 3. Análise de acidez pelo tempo (dia).

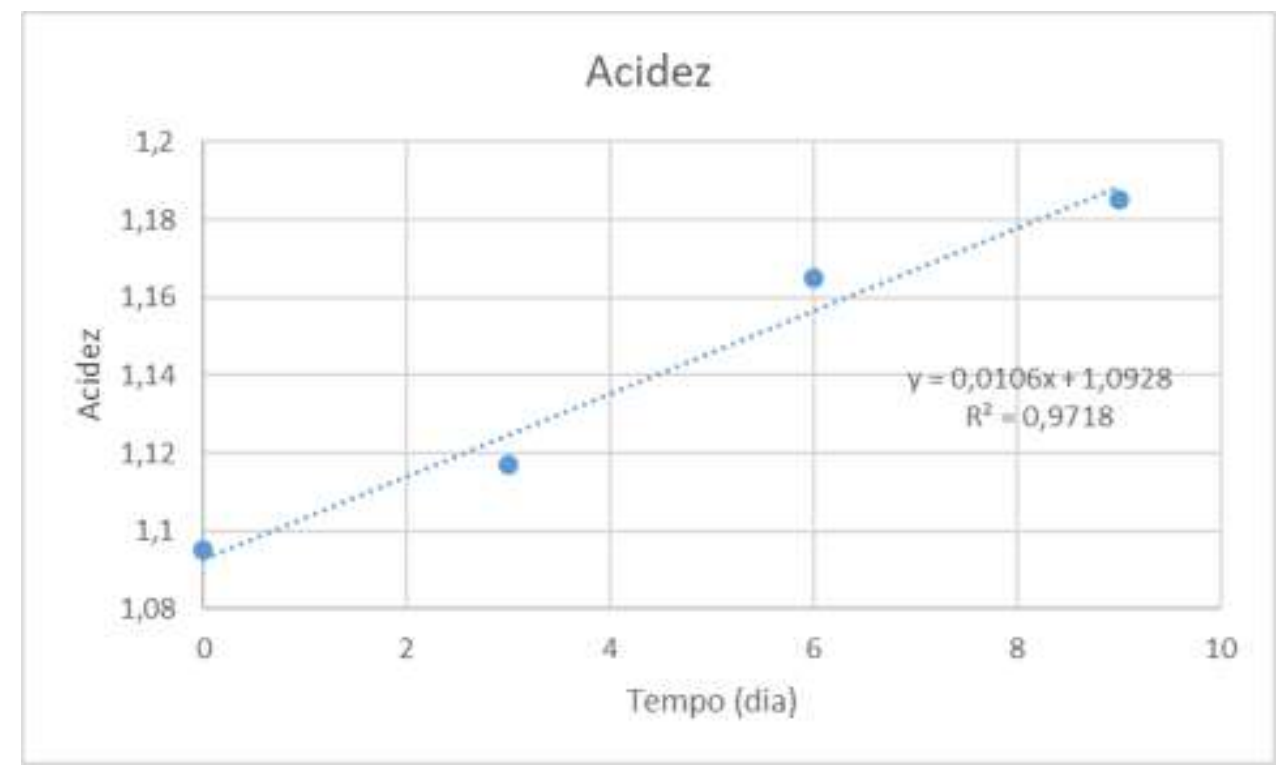

Fonte: Autores (2021).

O manjar de Kefir analisado apresentou teor de gordura de 8,51 \pm 0,25 (Tabela 3) e segundo Marchi et al (2015), o fermentado de Kefir a 5\% apresentou um teor de Gordura de 5,85. Esse valor diverge com o encontrado neste experimento. Como foi utilizado neste trabalho uma composição com leite de coco e coco ralado que são fontes consideráveis de gordura, acredita-se que esses compostos tenham aumentado o teor de gordura, justificado por Lázaro (2012) que comenta que o leite de coco é constituído por $85 \%$ de gordura saturada e ácidos graxos aterogênicos, sendo 50\% láurico, 19,7\% mirístico, 9,5\% palmítico, $4 \%$ gordura monoinsaturados e $1 \%$ de poli-insaturados.

Pletsch (2019) analisou gelado comestível de Kefir adicionado de polpa de jabuticaba e morango apresentou um teor de gordura de 13,07 $\pm 1,59$, esse valor é inferior ao encontrado no Manjar, entretanto, assim como o Manjar o gelado comestível apresenta não só o fermentado de Kefir como a adição de fruta e os compostos para saborização.

O manjar apresentou teor de lactose a 2,805 \pm 0,018 (Tabela 3) apresentando uma concentração de Kefir de 1,66\%, no entanto Terra (2007), encontrou teor de lactose de 2,55 no Kefir fermentado durante $24 \mathrm{~h}$ a uma concentração de $8 \%$, este valor diferiu ao valor determinado neste experimento, isso pode ser justificado pela diferença entre a porcentagem de grãos de Kefir utilizadas durante o processo de fermentação. Santos et al. (2012) comentam que de acordo com seus estudos que avaliaram as características físico-químicas do filtrado do Kefir de leite, eles observaram uma queda do teor de lactose desse filtrado ao longo da fermentação que, após 36 horas de fermentação atingiu resultados abaixo do valor limite que pode ser consumido por indivíduos intolerantes à lactose.

Lopes (2019) apresentou um teor de lactose de 2,79 para o fermentado de Kefir a 5\% durante 24 horas. Essa proporção foi superior a utilizada para fermentação do Manjar, além disso, Terra (2007) comentam que se deve ter em mente que a composição dos grãos de Kefir variam conforme sua origem, preparação e substrato e isso pode interferir na quantidade de lactose.

O manjar apresentou teor de cálcio de 0,159 $\pm 0,44$ (Tabela 3), já Weschenfelder (2009), encontrou no fermentado de Kefir a $10 \%$ um teor de cálcio de 0,11 , similar ao encontrado no leite. Esse valor diferiu do manjar pois, diferentemente do Weschenfelder, o teor de cálcio não é proveniente somente do leite, mas também do leite de coco. 
Já para o teor de cinza, o manjar apresentou 0,679 \pm 0,038 que foi diferente dos valores encontrados por Weschenfelder et al (2011) que encontrou 0,89 para um período de fermentação de 24 horas e uma proporção de 10\% de Kefir. Este valor é superior ao encontrado no manjar (Tabela 3), isso porque para a elaboração do fermentado de Kefir, foi utilizado uma proporção de $2 \%$, o que implica menor valor no teor de cinzas.

Segundo Pietta e Palezi (2015), o iogurte de Kefir à base de mirtilo apresentou um teor de cinzas de 0,75, o valor é próximo ao encontrado no Manjar, além disso, os dois utilizam de frutas para saboriza-los o que pode ter interferido no teor de cinzas.

Tabela 3. Dados coletados a partir de análises físico-químicas complementares.

\begin{tabular}{cccc}
\hline $\begin{array}{c}\text { Teor de Gordura } \\
(\%)\end{array}$ & $\begin{array}{c}\text { Teor de Lactose } \\
(\%)\end{array}$ & $\begin{array}{c}\text { Teor de Cálcio } \\
(\%)\end{array}$ & $\begin{array}{c}\text { Sólidos totais } \\
(\%)\end{array}$ \\
\hline $8,51 \pm 0,25$ & $2,805 \pm 0,018$ & $0,159 \pm 0,44$ & $0,679 \pm 0,038$ \\
\hline
\end{tabular}

Fonte: Autores (2021).

\section{Considerações Finais}

Com o desenvolvimento do manjar de Kefir com coco, notou-se que a concentração de grãos de Kefir utilizada foi baixa e por isso o teor de lactose continuou alto, sendo necessário realizar mais experimentos para determinar uma concentração capaz de consumir totalmente a lactose. As demais análises se encontraram dentro do esperado.

Devido aos inúmeros benefícios associados ao consumo regular de Kefir e aos resultados encontrados nesse estudo, o presente trabalho deseja incentivar as pesquisas relacionadas ao tema, em busca de aumentar o acesso da população a esse probiótico tão pouco conhecido. Além disso, acreditamos ser necessário estudos para determinar e caracterizar a microbiota constituinte dos grãos de Kefir, para auxiliar em futuros estudos científicos.

\section{Agradecimentos}

Agradecemos à CNPq pelo apoio financeiro, à Capes, à UFTM pelo incentivo à pesquisa.

\section{Referências}

Almeida, A. P. A. D. S. (2018). A utilização do kefir e seus benefícios para a saúde: Revisão Integrativa. https://repositorio.ufu.br/bitstream/123456789/22302/1/Utiliza\%C3\%A7\%C3\%A3oKefirSa\%C3\%BAde.pdf.

Araújo, J.C, Ribeiro, N. M., Bezerra, K. C. B., \& Landim, L. A. D. S. R. (2020). Desenvolvimento de kefir em leite de coco babaçu. Research, Society and Development, 9(11), e3559119891- e3559119891. https://www.rsdjournal.org/index.php/rsd/article/view/9891/8859.

Brasil. (2005). Ministério da Saúde. Agência de Vigilância Sanitária. Métodos Físico-químicos para a análises de alimentos. (4a ed.), Agência Nacional de Vigilância Sanitária - Brasília: Ministério da Saúde, 2005

Brasil. (2007). Ministério da Agricultura, Pecuária e Abastecimento. Instrução Normativa no 46 de 23 de outubro de 2007. Regulamento Técnico de Identidade e Qualidade de Leites Fermentados. Diário Oficial da República Federativa do Brasil, Brasília, DF, 24 de out. 2007.

Cardoso, A. L. S. P., Tessari, E. N. C., Castro, A. G. M., Kanashiro, A. M. I., \& Gama, N. M. S. Q. (2001). Pesquisa de coliformes totais e coliformes fecais analisados em ovos comerciais no laboratório de patologia avícola de descalvado. Arquivos do Instituto Biológico, 68(1), 19-22. http://www.biologico.sp.gov.br/uploads/docs/arq/v68_1/4.pdf

Cassanego, D. B., dos Santos Richards, N. S. P., Mazutti, M. A., \& Ramírez-Castrillón, M. (2015). Leveduras: diversidade em kefir, potencial probiótico e possível aplicação em sorvete. Ciência e Natura, 37(5), 175-186. https://www.redalyc.org/pdf/4675/467547645019.pdf

Contim, L. S. R., Oliveira, I. M. A., \& Cardoso Neto, J. (2018). Avaliação microbiológica, físico-química e aceitação sensorial do kefir com polpa de graviola. Revista do Instituto de Laticínios Cândido Tostes, 73(1), 1-9. https://rilct.emnuvens.com.br/rilct/article/view/604

Coppola, M. D. M., \& Gil-Turnes, C. (2004). Probióticos e resposta imune. Ciência rural, 34(4), 1297-1303. 
Costa, E., dos Santos, J. B. D. R., Pereira, M. C., \& Mello, F. F. (2018). Aspectos físico-químicos e funcionais de bebida látea fermentada com kefir enriquecida com amora-preta (RUBUS SP.). Anais do Salão Internacional de Ensino, Pesquisa e Extensão, 10(2). https://periodicos.unipampa.edu.br/index.php/SIEPE/article/view/100260

Costa, M. de S., et al. Avaliação das propriedades físicas de ameixa preta (prunus domestica) submetida a desidratação osmótica. 2018.

Costa, M. D. S., de Araújo, A. C., \& Andrade, K. T. (2018). Avaliação das propriedades físicas de ameixa preta (prunus demestica) submetida a desidratação osmótica. https://www.confea.org.br/sites/default/files/antigos/contecc2018/agronomia/32_adpfdappdsado.pdf

Dias, P. A., Silva, D. T., \& Timm, C. D. (2018). Atividade antimicrobiana de microrganismos isolados de grãos de kefir. Ciência Animal Brasileira, 19 https://www.scielo.br/j/cab/a/cX9Wq4CJGMrfZPKm4B4WWBS/?lang=pt\&format=html

Dias, P. A., Rosa, J. V. D., Tejada, T. S., \& Timm, C. D. (2016). Propriedades antimicrobianas do kefir. Arquivos do Instituto Biológico, 83. https://www.scielo.br/j/aib/a/KkXT6rwf8HyrcwdBC97m8vR/abstract/?lang=pt

Dornelles, A. S., Rodrigues, S., \& Garruti, D. D. S. (2009). Aceitação e perfil sensorial das cachaças produzidas com Kefir e Saccharomyces cerevisae. Food Science and Technology, 29, 518-522.: https://www.scielo.br/scielo.php?pid=S0101-20612009000300010\&script=sci_arttext.

Dornelles, A. S., \& Rodrigues, S. (2006). Fermentação alcoólica de caldo de cana utilizando grãos de kefir. Revista Ciência Agronômica, 37(3), 386-390. http://www.ccarevista.ufc.br/seer/index.php/ccarevista/article/view/171/165. Acesso em: 14 nov. 2020.

Gonçalves, I. F., Martins, E. M. F., Silva, V. R. O., \& de Oliveira Martins, A. D. (2018). Efeito de yacon na aceitação sensorial de kefir e viabilidade de bactérias láticas na bebida.

Lázaro, C. P. (2012). Efeito do leite de coco sobre o perfil lipídico de indivíduos jovens. http://www7.bahiana.edu.br/jspui/handle/bahiana/48

Lopes, L. C. (2019). Teor de lactose e contagem de microrganismos em leites fermentados por kefir: um estudo comparativo. http://168.197.92.160/handle/10899/20835

Machado, L. M. I., \& Gonçalves, M. P. M. (2019). Aceitabilidade de iogurte a base de Kefir enriquecido com suco de uva integral (Vitis vinífera). https://servicos.unitoledo.br/repositorio/bitstream/7574/2186/1/Aceitabilidade $\% 20 \mathrm{de} \% 20$ iogurte $\% 20 \mathrm{a} \% 20 \mathrm{base} \% 20 \mathrm{de} \% 20 \mathrm{kefir} \% 20 \mathrm{enriquecido} \% 20 \mathrm{com} \% 20 \mathrm{~s}$ uco $\% 20 \mathrm{de} \% 20 \mathrm{uva} \% 20 \mathrm{integral} \% 20 \% 28$ Vitis\%20Vinifera\%29\%20-\%20La\%c3\%adsa\%20Mirella\%20Igarashi\%20Machado.pdf

Matta, C.M.B et al. Probiócos e prebióticos. (2009). Revista Funcionais Nutracêuticos. https://maua.br/files/artigos/artigo-probioticos-e-prebioticos.pdf.

Moraes, F. P., \& Colla, L. M. (2006). Alimentos funcionais e nutracêuticos: definições, legislação e benefícios à saúde. Revista eletrônica de farmácia, 3(2). https://www.revistas.ufg.br/REF/article/view/2082/2024

Oliveira, M. N. D., Sivieri, K., Alegro, J. H. A., \& Saad, S. M. I. (2002). Aspectos tecnológicos de alimentos funcionais contendo probióticos. Revista Brasileira de Ciências Farmacêuticas, 38, 1-21. https://www.scielo.br/j/rbcf/a/rvzMDX5X9JB4pxjq4rFggrv/?format=pdf\&lang=pt

Paiva, I. M. (2013). Caracterização estrutural e avaliação da capacidade imunomodulatória de exopolissacarídeos produzidos por lactobacilos isolados de Kefir. https://repositorio.ufmg.br/handle/1843/BUOS-96DG2X

Pletsch, L. B. H., Severo, J., Hermanns, G., \& Preichardt, L. D. (2019). Gelado comestível de kefir adicionado de polpa de jabuticaba e morango. Revista do Instituto de Laticínios Cândido Tostes, 74(1), 39-50. https://www.revistadoilct.com.br/rilct/article/view/701

Pietta, G. M., \& Palezi, S. C. (2015). Desenvolvimento de um iogurte sabor mirtilo à base de kefir e com reduzido teor de lactose. Unoesc \& CiênciaACET, 6(2), 163-172. https://unoesc.emnuvens.com.br/acet/article/view/8000/5076

Ribeiro, A. S. (2015). Caracterização de micro-organismos com potencial probiótico isolados a partir de kefir produzidos na Região Noroeste do Estado do Rio Grande do Sul

Santos, A. V. D. (2012). Desenvolvimento de produtos lácteos fermentados por grãos de kefir com teor de colesterol reduzido e saborizados com frutas tropicais. https://mestrados.unit.br/wp-content/uploads/2013/03/Dissert.-PEP-Alysson-Vieira-dos-Santos.pdf.

Santos, F. L. et al. Kefir: uma nova fonte alimentar funcional? Diálogos \& Ciência (Online), 10, 1-14, 2012.

Santos, F. L., Silva, E. O., Barbosa, A. O., \& Silva, J. O. (2012). Kefir: uma nova fonte alimentar funcional. Diálogos \& Ciência (Online), 10, 1-14. https://www2.ufrb.edu.br/kefirdoreconcavo/images/22_03_12_artigo01.pdf

Silva, E. M. (2019). Aceitabilidade de iogurte a base do leite fermentado de kefir saborizado com geleia de banana da prata. http://131.0.244.66:8082/jspui/bitstream/123456789/1581/1/Elivelton\%20Melo\%20Silva.pdf.

Silva, N., Junqueira, V. C. A., de Arruda Silveira, N. F., Taniwaki, M. H., Gomes, R. A. R., \& Okazaki, M. M. (2007). Manual de métodos de análise microbiológica de alimentos e água. Editora Blucher.

Souto, C. S., Silva, P. P., \& Neif, É. M. (2020). Kefir e seu potencial probiótico. Revista Eletrônica Interdisciplinar, 12(1), 024-034. http://revista.sear.com.br/rei/article/view/44/36

Terra, F. M. (2007). Teor de lactose em leites fermentados por grãos de kefir. https://bdm.unb.br/handle/10483/185

TussolinI, L et al. (2009). Atividade antibiótica de bactérias lácticas isoladas do kefir frente à Escherichia coli, Staphylococcus aureus e Salmonella Typhimurium. https://anais.unicentro.br/siepe/isiepe/pdf/resumo_371.pdf. 
Research, Society and Development, v. 10, n. 10, e154101018543, 2021

(CC BY 4.0) | ISSN 2525-3409 | DOI: http://dx.doi.org/10.33448/rsd-v10i10.18543

Villanoeva, C. N. B. C. (2016). Avaliação da qualidade microbiológica e físico-química de kefir e da atividade biológica da bebida, de Lactobacillus spp. isolados de diferentes grãos e exopolissacarídeos. https://repositorio.ufmg.br/handle/1843/35501

Weschenfelder, S. (2009). Caracterização de kefir tradicional quanto à composição físico-química, sensorialidade e atividade anti-Escherichia-coli. https://www.lume.ufrgs.br/handle/10183/16409 